\title{
A Single Approach for Management of Fractures Involving Both Columns of the Acetabulum: A Case Series of 23 Patients
}

\author{
Atul Patil ${ }^{1}$, Dheeraj S Attarde ${ }^{2}$, Askhar Haphiz ${ }^{3}$, Parag Sancheti ${ }^{4}$, Ashok Shyam $^{5}$
}

\begin{abstract}
Aim and objective: To study the radiological and functional outcomes as well as complications in the management of fractures involving both columns of the acetabulum using a single surgical approach.

Design: Type IV, prospective clinical study.

Setting: Level I trauma centre.

Materials and methods: Inclusion criteria were as follows: (a) patients over 20 year of age and (b) patients suffering from acetabular fractures involving both columns as per Letournel and Judet classification, namely transverse, transverse + posterior wall, T type, anterior column posterior hemi-transverse (ACPHT) and associated both columns. Exclusion criteria were as follows: (a) patient suffering from isolated anterior column, posterior column, anterior wall, posterior wall and posterior wall + column fractures; (b) patient who have undergone surgical procedures of the hip prior to trauma; and (c) compound acetabular fractures. A total of 23 patients having both column acetabulum fractures were included prospectively from June 2016 to December 2018 and followed up till 1 year postoperatively. Open reduction and internal fixation were performed through one of three described approaches, i.e., iliofemoral, Kocher-Langenbeck, and anterior intrapelvic or ilioinguinal.

Results: Our study population consisted of $30.4 \%$ transverse, $39.1 \%$ associated both columns, $21.7 \% \mathrm{~T}$ type and $8.7 \%$ anterior column + posterior hemi-transverse. Of these, $65.2 \%$ were operated using the Kocher-Langenbeck approach, while $30.4 \%$ of patients required the anterior intrapelvic approach. The remaining $4.3 \%$ of patients were operated by the iliofemoral approach. Anatomic reduction was achieved in $100 \%$ of our study population with remaining displacement less than or equal to $1^{\circ} \mathrm{mm}$. At 1-year follow-up, all fractures showed a satisfactory union with an excellent Matta index in $100 \%$ study subjects. Complications at 1 year included one case of foot drop, which was present preoperatively but failed to improve and one case of post-traumatic arthritis. Average Harris Hip score (HHS) and mean Merle D'Aubigne (MDA) scores suggested good clinical outcomes in the study population.

Conclusions: A single approach can be used to achieve good functional and radiological outcomes in carefully selected bicolumnar fractures of the acetabulum, with less approach-related morbidity.

Clinical significance: Traditionally, multiple approaches are used for acetabulum fractures involving both columns, but with proper patient selection, single approach can be used with good functional and surgical outcomes.

Keywords: Acetabular fracture, Bicolumnar fracture acetabulum, Single-approach acetabulum.

Strategies in Trauma and Limb Reconstruction (2021): 10.5005/jp-journals-10080-1541
\end{abstract}

\section{INTRODUCTION}

Surgical management has become the standard of care to treat displaced acetabular fractures over the past 50 years. ${ }^{1,2}$ While accounting for only about $2 \%$ of all fractures, these fractures are associated with significant morbidity and mortality in view of their close proximity to vital structures and high-energy trauma they are associated with. ${ }^{3-6}$ Studies have shown good clinicoradiological results and functional outcomes with early and goodquality open reduction and internal fixation of these fractures. ${ }^{7,8}$

The use of an appropriate surgical approach is pivotal in attaining good radiological and clinical results. ${ }^{9,10}$ Surgical approaches to the acetabulum may be anterior, posterior, extensile or combined. There have been multiple attempts in the past to use a single approach to tackle complex fractures of the acetabulum, and they were, to an extent, able to reduce the rate of exposure-related morbidity. ${ }^{11}$ Some of these studies, however, showed inferior clinical outcomes in comparison with studies using extensile approaches. ${ }^{12,13}$ Extensile and combined approaches allow better visualisation of the fracture and facilitate better instrument placement, result in better radiological outcomes but have been plagued with greater incidence of approach-related morbidity.
${ }^{1}$ Department of Trauma, Sancheti Institute for Orthopaedics and Rehabilitation, Pune, Maharashtra, India

${ }^{2-5}$ Department of Orthopaedics, Sancheti Institute for Orthopaedics and Rehabilitation, Pune, Maharashtra, India

Corresponding Author: Dheeraj S Attarde, Department of Orthopaedics, Sancheti Institute for Orthopaedics and Rehabilitation, Pune, Maharashtra, India, Phone: +91 9049624952, e-mail: dheerajattarde@yahoo.co.in

How to cite this article: Patil A, Attarde DS, Haphiz A, et al. A Single Approach for Management of Fractures Involving Both Columns of the Acetabulum: A Case Series of 23 Patients. Strategies Trauma Limb Reconstr 2021;16(3):152-160.

Source of support: Nil

Conflict of interest: None

Problem with dual approach was that it was performed either in staged sitting or in the same sitting: one side is fixed first and then opposite side was addressed. This situation makes it difficult if surgeon decides to revisit another column for revision during surgery. ${ }^{13}$ Most studies that exist in recent literature have tried to

(c) The Author(s). 2021 Open Access This article is distributed under the terms of the Creative Commons Attribution-Non Commercial-share alike license (https://creativecommons.org/licenses/by-nc-sa/4.0/) which permits unrestricted distribution, and non-commercial reproduction in any medium, provided you give appropriate credit to the original author(s) and the source, provide a link to the Creative Commons license, and indicate if changes were made. If you remix, transform, or build upon the material, you must distribute your contributions under the same license as original. The Creative Commons Public Domain Dedication waiver (http://creativecommons.org/publicdomain/zero/1.0/) applies to the data made available in this article, unless otherwise stated. 
show how one of the many described approaches was superior to the others in attaining improved clinical and radiological outcomes. ${ }^{14,15}$ Studies that selected one of the three commonly used approaches based primarily on the fracture geometry are lacking.

In this retrospectively reviewed prospective study, we evaluated the use of a single approach for fractures involving both columns of the acetabulum in terms of resultant radiological outcome, functional assessment scores and complications arising out of the fracture or the surgical exposure or both.

\section{Materials and Methods}

After obtaining formal institutional review board and ethical committee approval (IRB number-SIOR/agenda/049), patients admitted with acetabular fractures involving both columns of the acetabulum $(n=23)$ between June 2016 and December 2018 were included. Patients with isolated anterior column, posterior column, anterior wall, posterior wall and posterior wall and column fractures were excluded from the study in addition to patients who had undergone surgical procedures of the hip prior to trauma. Patients suffering from pathological and compound fractures of the acetabulum were also excluded from this study. Patients were divided into three groups according to the approach used. The HHS, MDA and SF-36 scores were calculated at 1-month, 3-month, 6-month and 1-year follow-up.

\section{Initial Assessment and Classification of Fracture}

Detailed history and examination as per ATLS protocol were undertaken. Stabilisation of the fracture by the use of appropriate skeletal traction was done. A history of any associated medical comorbidity or any other relevant history, which would alter the treatment plan, e.g., drug intake, preinjury ambulation status, was noted. Radiographic evaluation was of the pelvis with a view of both hips, both Judet views, and a CT scan to assess the fracture in detail. Using the Letournel and Judet classification, ${ }^{3} 39.1 \%$ were associated both-column, 30.4\% transverse, 21.7\% T-type and $8.7 \%$ anterior column posterior hemi-transverse types of fractures.

The study population consisted primarily of male patients (78.3\%), with the most common mechanism of injury being road traffic accidents (79.3\%). The average age of patients was 45.77 years (Fig. 1).

\section{Treatment}

No randomisation was made for surgical treatment. Fixation of the fracture was carried out according to fracture type.

The decision regarding surgical approach to be used was based on the fracture pattern. Preoperative X-rays and CT scans were studied to ascertain which column among the two was displaced to a greater extent. Surgery was done using Kocher Langenbeck, iliofemoral or modified anterior intrapelvic approaches. The mean timing of surgery from injury was 2.8 days. An open exposure of the maximally displaced column was then undertaken using one of the three described approaches followed by fixation using contoured reconstruction plates. This led to reducing the displacement or, in some cases, complete reduction of the second column, making it amenable to fixation by a column-specific screw or buttress plate inserted through the same approach under intensifier guidance (Flowchart 1).

Surgical approach used and intraoperative complications (if any) were recorded. The most commonly used surgical approach was the Kocher-Langenbeck approach in $65.2 \%$ of patients followed by anterior intrapelvic approach in $30.4 \%$ of patients and iliofemoral in $4.3 \%$ of patients. Immediate post-operative AP and Judet views were taken. The quality of reduction was assessed as per Matta's radiological criteria (for anatomic reduction). Postoperatively, all patients were kept in bed for 2 weeks, followed by non-weightbearing mobilisation with the help of a walker for another 2 weeks. Partial weight bearing was started at 1 month, which was increased to full weight bearing at 4 months. All patients had deep vein thrombosis (DVT) prophylaxis in the form of subcutaneous low molecular weight heparin for the first 2 weeks post-surgery or when assisted pain-free ambulation was achieved, whichever came earlier. This was followed by low-dose aspirin for another month. All patients were reviewed clinically and radiologically at 3,6 and 12 months.

\section{Bone Union and Functional Outcome}

All patients were monitored and followed up for a period of 1 year (Table 1). The patients underwent clinical examination of hip range of motion, VAS score, limb shortening, and degree of ambulation

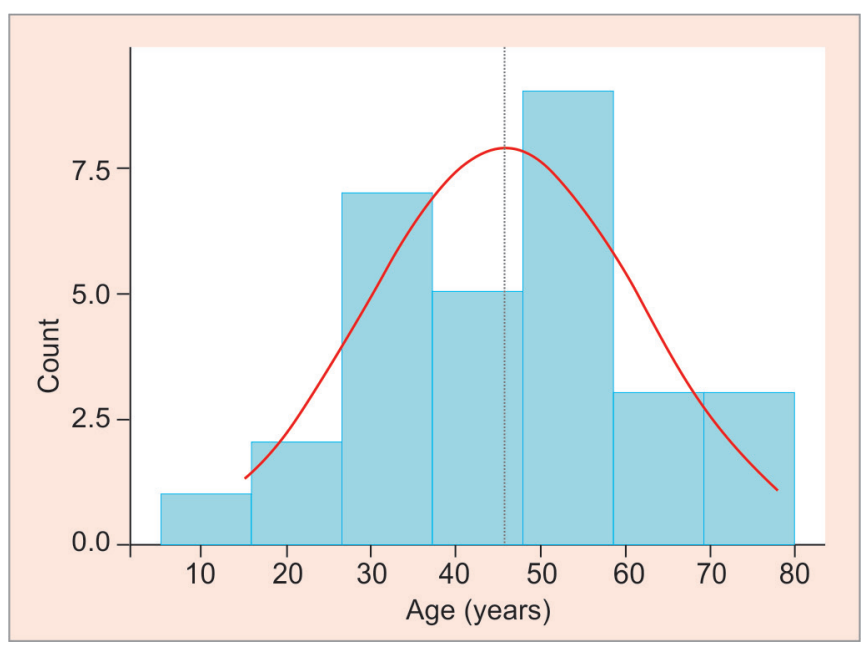

Fig. 1: Age distribution

Flowchart 1: Algorithm to determine approach based on column involved

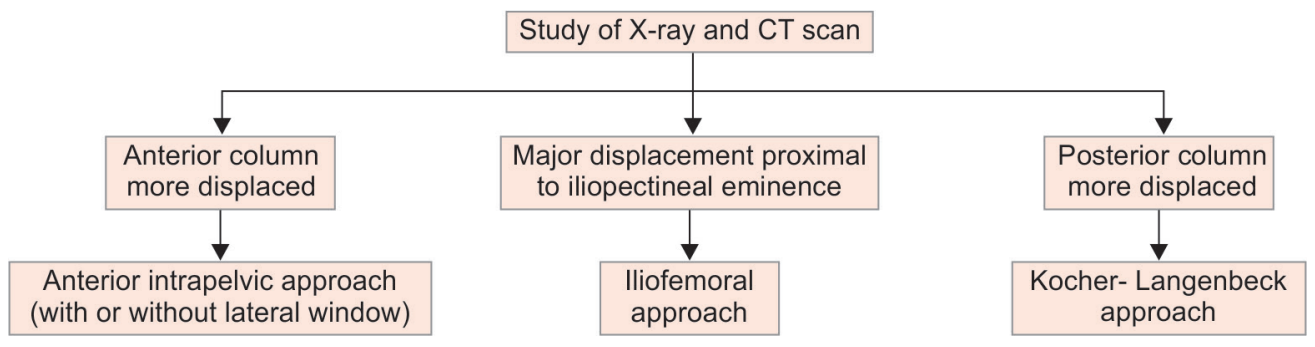


at the follow-up. Radiological assessment of fracture healing was done using X-ray and graded using Matta's index. Clinical outcome evaluation was carried out with the modified Merle d'Aubigne (MDA) score, Harris Hip score (HHS), and SF-36 questionnaire at 1 year of follow-up.

\section{Statistical Analysis}

Data were coded and recorded in MS Excel spreadsheet program. SPSS v23 (IBM Corp.) was used for data analysis. Descriptive statistics were elaborated in the form of means and standard deviations or

Table 1: Demographic data and outcomes at 1-year follow-up

\begin{tabular}{lc}
\hline Gender & \\
Male & $18(78.3 \%)$ \\
Female & $5(21.7 \%)$ \\
Mechanism of injury & \\
RTA & $17(73.9 \%)$ \\
Fall & $5(21.7 \%)$ \\
Blunt trauma & $1(4.3 \%)$ \\
Diagnosis & \\
Transverse & $7(30.4 \%)$ \\
T-type & $5(21.7 \%)$ \\
AC + PHT & $2(8.7 \%)$ \\
Associated both column & $9(39.1 \%)$ \\
Mean timing of surgery (days) & 2.8 \\
Approach used & \\
Kocher-Langenbeck & $15(65.2 \%)$ \\
Anterior intrapubic & $7(30.4 \%)$ \\
Iliofemoral & $1(4.3 \%)$ \\
VAS (12 months) & $0.00 \pm 0.00$ \\
Active SLR (months) & $3.74 \pm 0.69$ \\
Cross-legged sitting (months) & $9.17 \pm 0.39$ \\
Driving 4-wheeler (months) & $5.25 \pm 0.68$ \\
Driving 2-wheeler (months) & $8.93 \pm 0.70$ \\
HHS & $85.48 \pm 2.87$ \\
MDA & $14.95 \pm 3.46$ \\
\hline
\end{tabular}

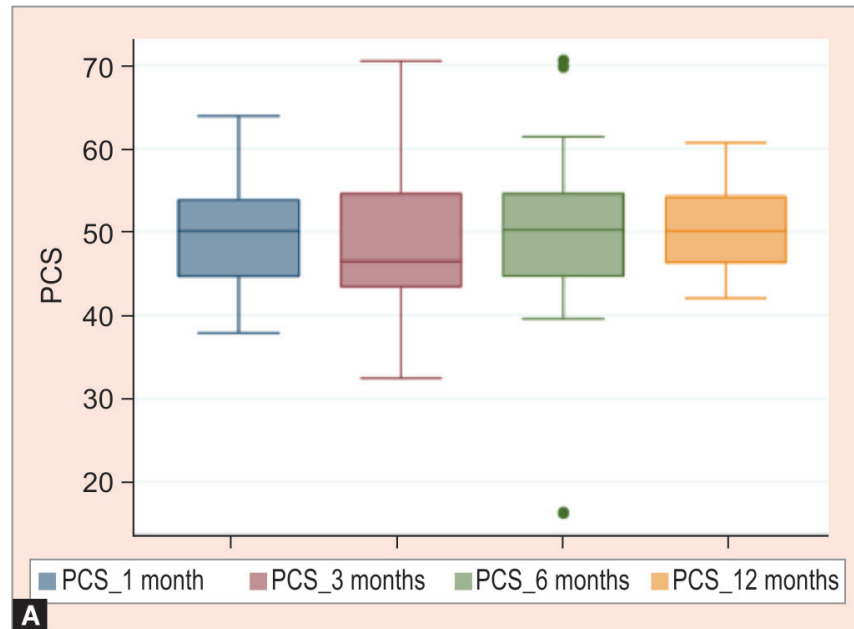

medians and IQRs for continuous variables, and frequencies and percentages for categorical variables. Data were presented in a graphical manner wherever appropriate for data visualisation. Group comparisons for continuously distributed data were made using ANOVA. Statistical significance was kept at $p<0.05$.

\section{Results}

An acceptable anatomical reduction with good articular congruity as per the Matta criteria on radiographs was achieved in $100 \%$ cases of our study sample. ${ }^{16}$ All surgical wounds healed well without any superficial or deep infection. No reduction loss nor thromboembolic complications were noted, while all 23 fractures united at 1-year follow-up.

Our study subjects attained an active SLR at an average of $3.4( \pm 0.69)$ months. They were able to resume driving at 5.2 $( \pm 0.68)$ months, use a motorcycle at $8.9( \pm 0.70)$ months and cable to sit cross-legged at $9.1( \pm 0.39)$ months post-surgery.

The mean MDA score at 1-year follow-up was $14.95( \pm 3.46)$ representative of a good functional result, with average HHS of $85.48( \pm 2.97)$, also suggestive of good clinical outcome.

A group analysis was performed with respect to HHS, MDA, and SF-36 scores among all three groups (Fig. 2). The HHS and

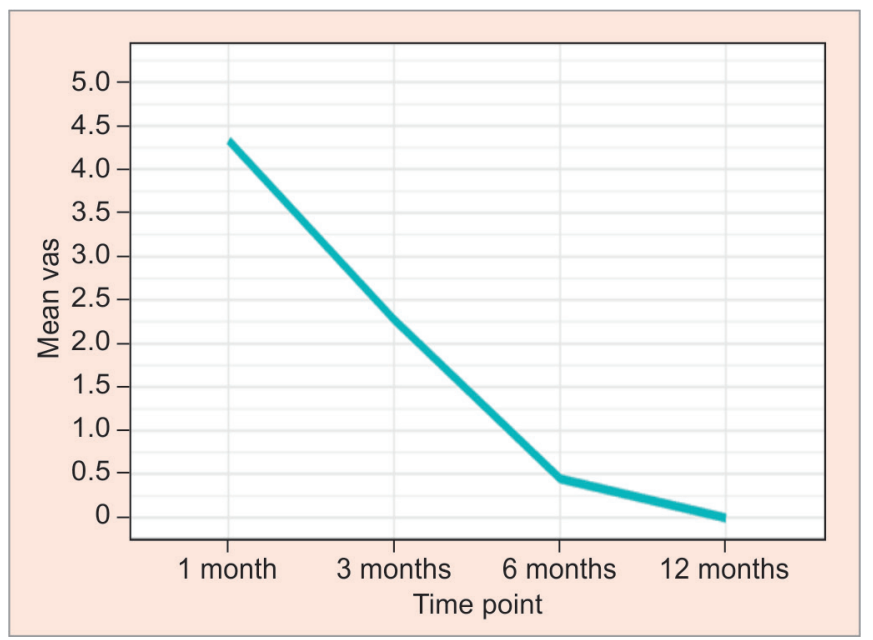

Fig. 2: VAS at 3, 6, and 12 months

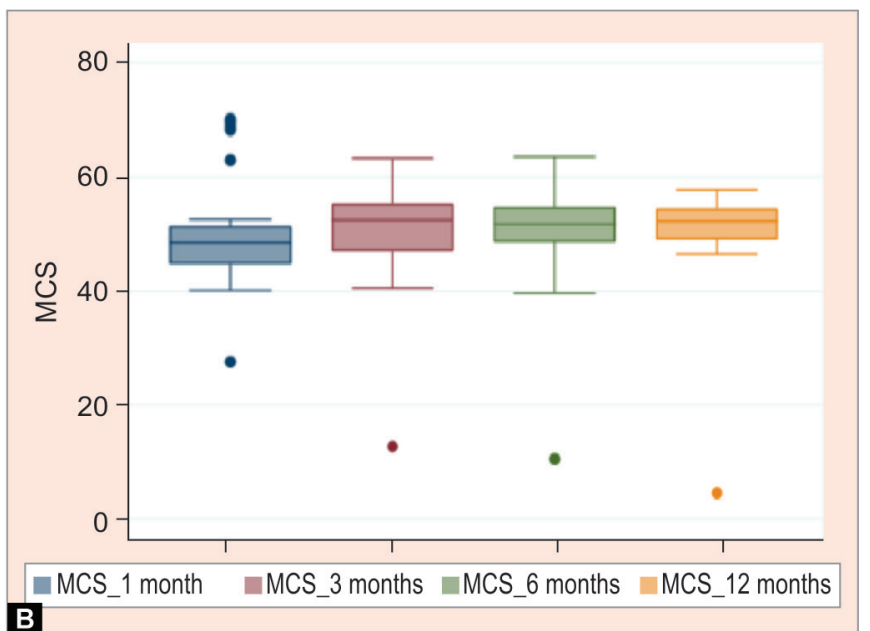

Figs $3 \mathrm{~A}$ and B: Box and Whisker chart showing MCS and PCS components at the follow-up 

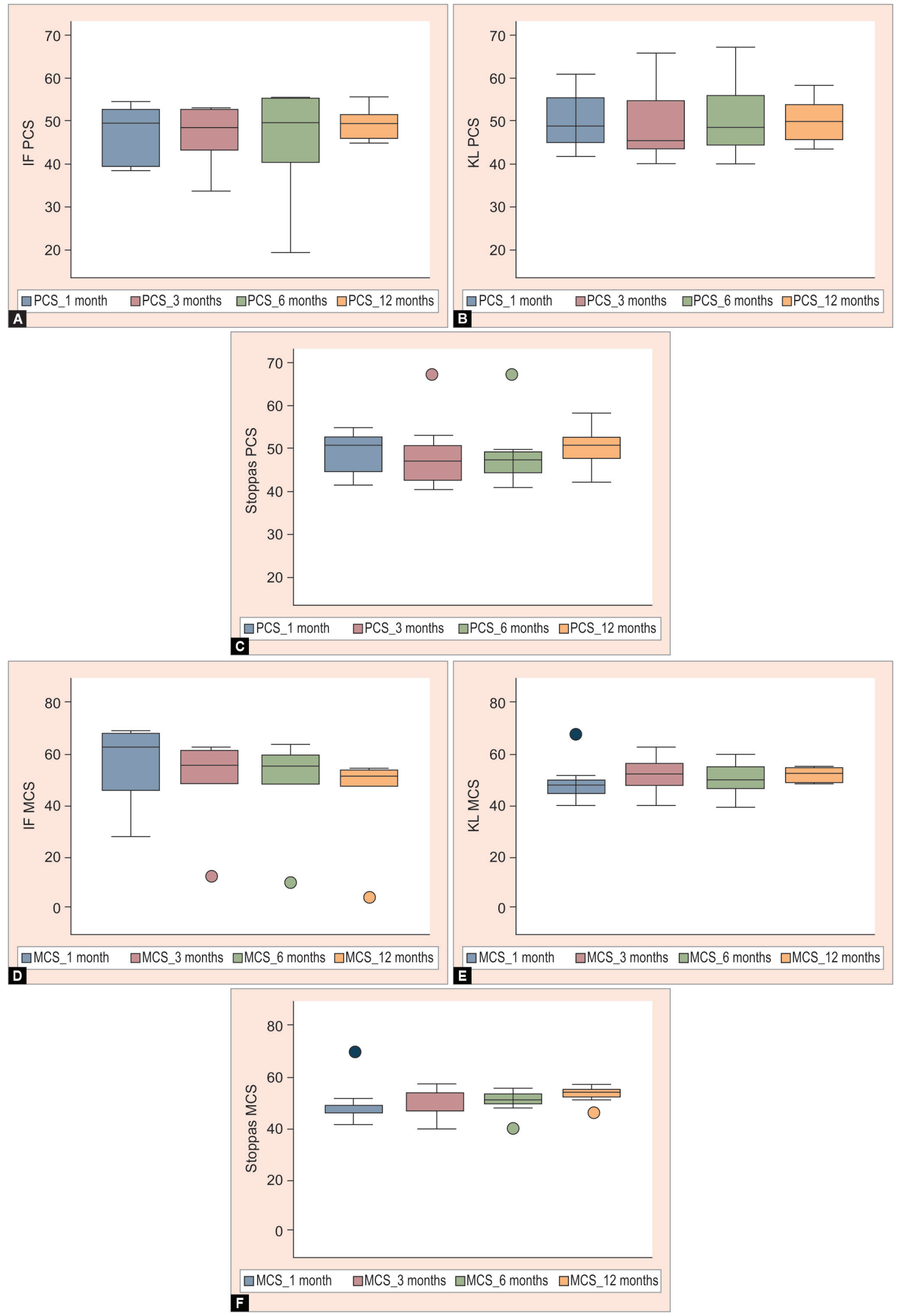

Figs 4A to F: Box and Whisker chart showing MCS and PCS scores among three different groups IL, lliofemoral; KL, Kocher-Lagenbeck and Stoppas 

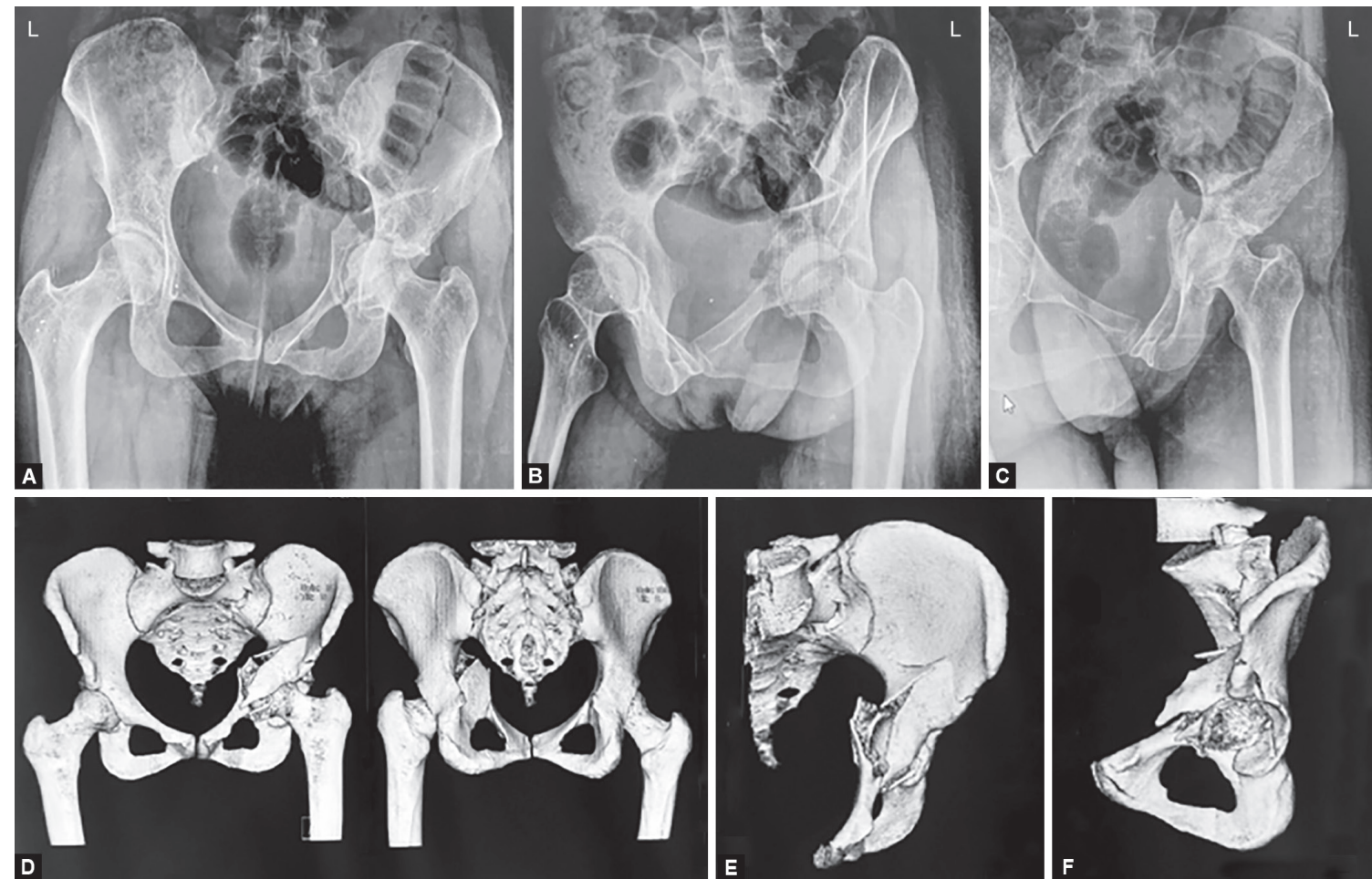

Figs 5A to F: Preoperative radiographs and CT scan showing bicolumnar fracture

MDA scores of three groups were compared using ANOVA at 1st-, 3rd-, and 6th-month, and 1-year follow-up. There was no statistical difference observed. A similar analysis of the PCS and MCS scores of all patients from the SF-36 suggested no significant difference between the mean scores in both. The PCS comparison among all three groups showed comparable means, while the mean MCS score was higher for Stoppa group. The PCS score was reduced at 3 months among all groups and increased again at the final follow-up. The MCS score of iliofemoral (IF) and Kocher-Langenbeck (KL) approach groups increased at 3 months but decreased at 1-year follow-up, while for the Stoppa group, the MCS score was more at the final 1-year follow-up (Figs 3 and 4).

Up to the last follow-up, none had avascular necrosis of the femoral head or heterotopic ossification. One patient had preoperative foot drop, which failed to recover spontaneously and is awaiting a tendon transfer for the same. One patient was noted to have post-traumatic arthritis of the hip joint and is currently being managed conservatively.

\section{Discussion}

The discussion regarding which surgical approach to use is probably as old as internal fixation of these fractures itself. It has been undergoing continued evolution with our better understanding of these complex fractures and advances in instrumentation, imaging techniques, and surgical training. ${ }^{17,18}$

The choice of exposure must be determined primarily by fracture morphology and secondarily by the surgeon's training and experience. The choice of approach was based on an algorithm, which took into consideration which of the two columns was maximally displaced (Figs 5 to 11). We observed that the reduction and plating of the more displaced column by a suitable open approach, in most cases, led to better congruity of the other column. This, in turn, enabled fixation of the other, less displaced column by an anti-glide plate or a column-specific screw inserted through the same approach. This method of fixation has been shown to be sufficient to resist stresses produced by active movement. ${ }^{12}$

The literature suggests that lag-screw fixation in addition to plate-screw construct provides greater resistance to deforming forces. ${ }^{19}$ The absence of loss of reduction in our study can be attributed to fixation of the second column with a lag screw or the combination of a lag screw with a buttress plate.

There have been multiple attempts in the past to use a single approach to tackle complex fractures of the acetabulum (Fig. 2). ${ }^{14,20}$ Isaacson et al. ${ }^{20}$ in 2014 in an evaluation of the Modified Stoppa approach in the management of bicolumn acetabulum fractures were able to achieve radiological results at par with existing literature for fractures which predominantly had displaced anterior columns. They, however, noticed a lower quality of results when posterior column involvement was added to the equation, which prompted them to conclude that modified Stoppa may not be the best approach for fractures primarily involving the posterior column.

Xue et al. ${ }^{14}$ used a novel Pubic symphysis approach to treat a series of 15 patients with acetabular fractures. Being minimally invasive, this approach had better outcomes in terms of approachrelated morbidity. However, the requirement of an additional Kocher-Langenbeck approach in more than $50 \%$ of the study population again showed the inadequacy of any single approach in being used to effectively treat all bicolumnar fractures.

Another pertinent study by Hue et al. ${ }^{21}$ stated the importance of reserving extensile approaches such as the extended iliofemoral 

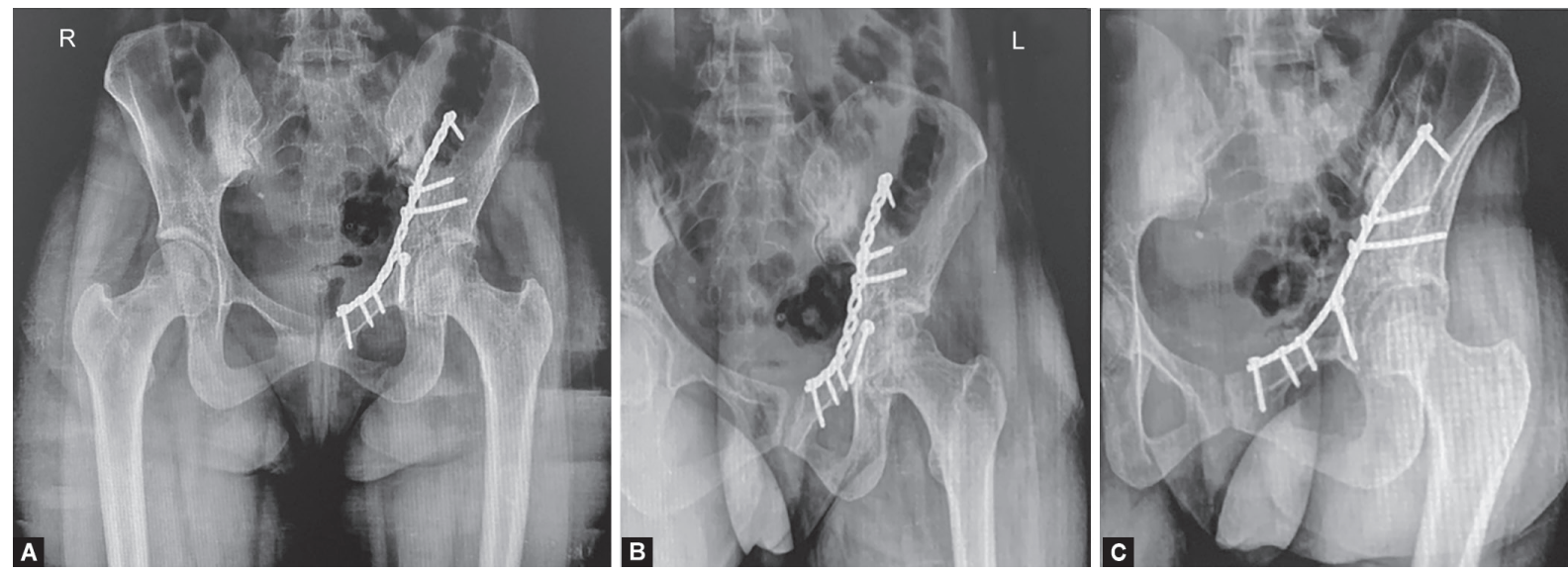

Figs 6 A to C: Immediate post-operative radiographs showing good reduction through AIP approach
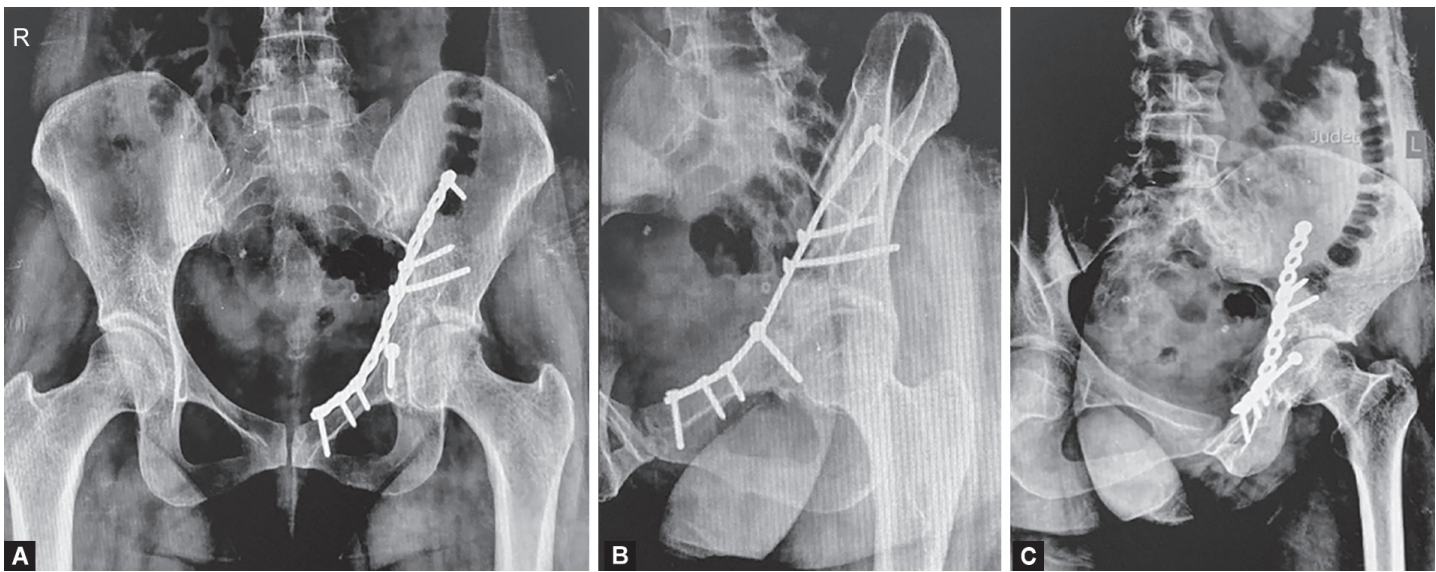

Figs 7A to C: 1-year follow-up radiographs showing good osseous union
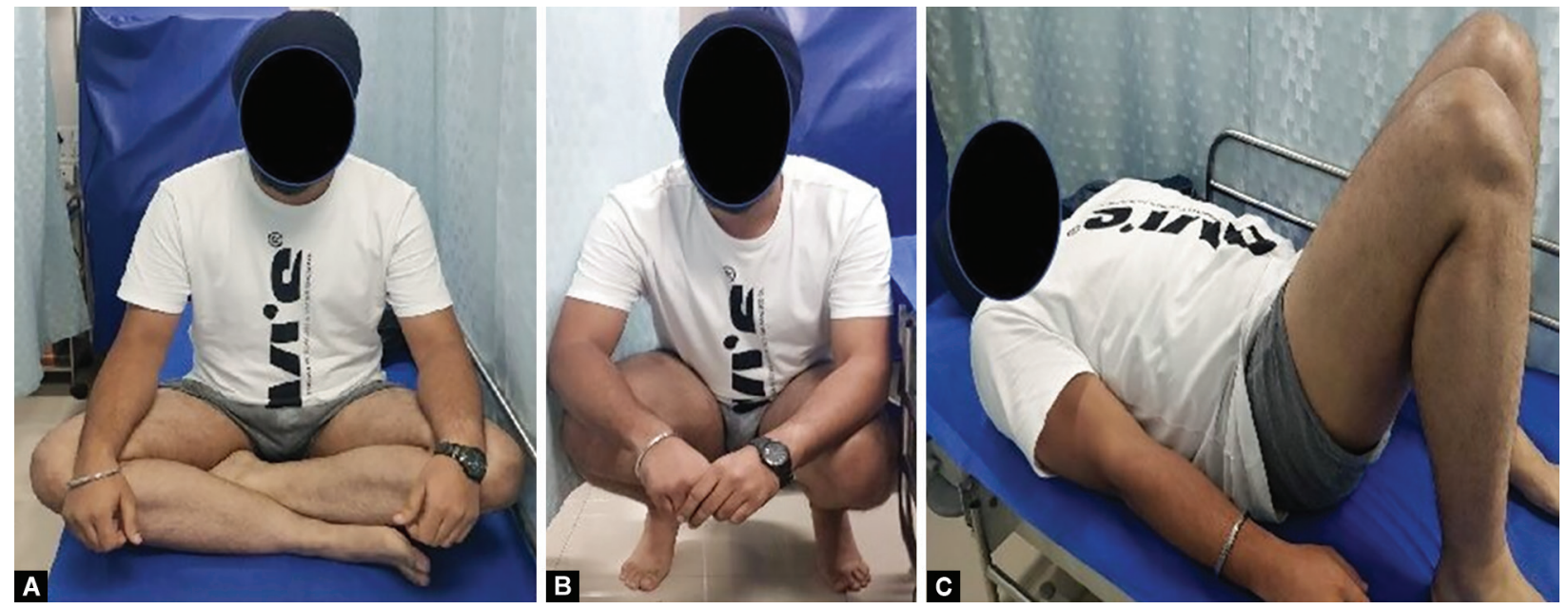

Figs $8 \mathrm{~A}$ to $\mathrm{C}$ : Clinical outcome at 1 year

only for cases requiring such extensive exposure of the acetabulum as they may result in excellent radiological outcomes alone without proportionate clinical and functional outcomes.

Chen et al. ${ }^{15}$ used a modification of the ilioinguinal approach to manage 22 cases and were able to attain excellent to good results with minimal approach-related complications, thereby reinstating that a single-approach methodology can lead to improved outcomes provided subjects are appropriately selected. The modification of the ilioinguinal approach to reduce soft tissue dissection was probably the main reason for fewer complications compared to the classically described approach. 


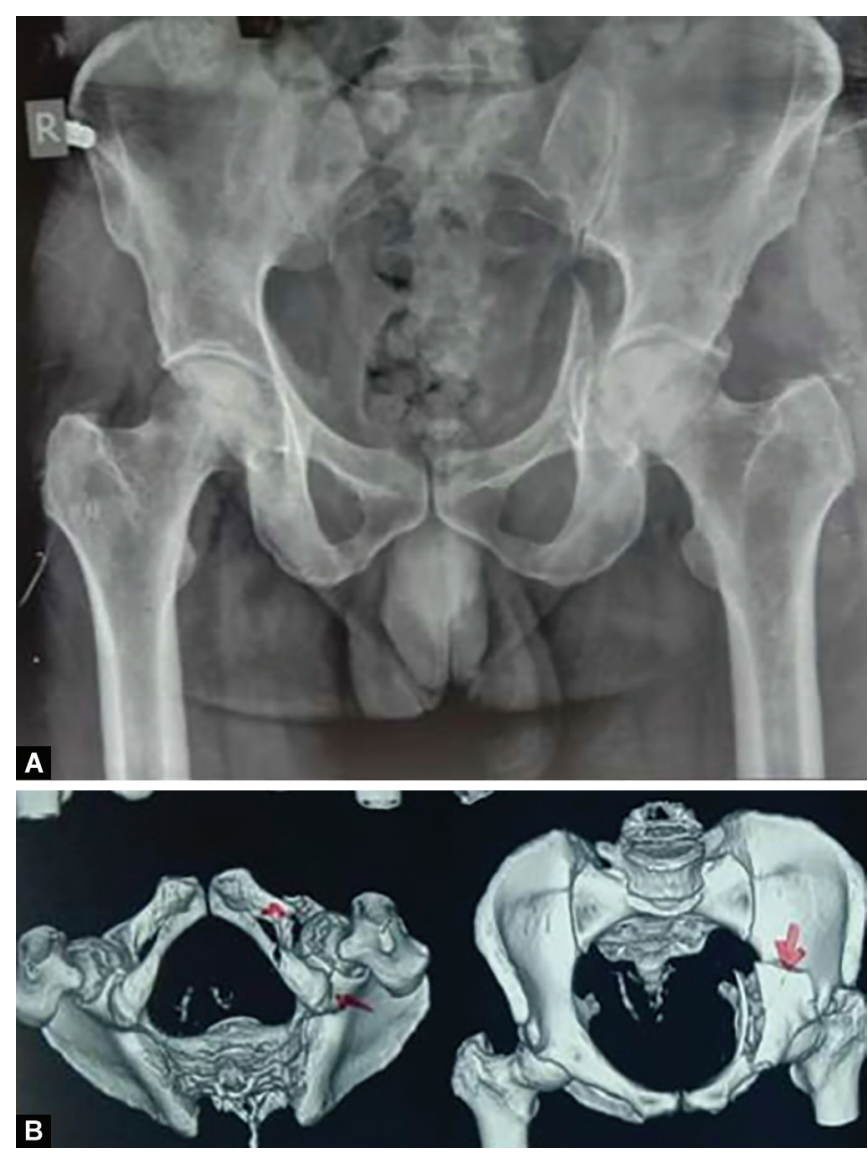

Figs 9A and B: Preoperative radiograph and CT scan showing bicolumnar acetabulum fracture

A single-approach methodology avoids staged surgeries as well as intraoperative position changes. ${ }^{22}$ This not only reduces approach-related morbidity and complications associated with prolonged recumbency but also aids in preventing inaccessibility of the initially fixed immobile column, thereby further achieving good reduction of the second column and also reducing operative time (Table 2). ${ }^{23}$

It must, however, be kept in mind that the method we have used is recommended only for fracture patterns where one column is fixable by column screws or anti-glide plates and the presence of fracture displacement or patterns not amenable to such an approach should prompt the surgeon to use additional approaches in the same sitting or in a staged manner.

The MDA score ${ }^{24}$ and $\mathrm{HHS}^{25}$ at 1-year follow-up in our study population were in the excellent or good range (Table 1) and were found to be better than rates seen in the existing literature. ${ }^{26,27}$ Also, complications noted included one case each of preoperative foot drop (4.3\%) and post-traumatic arthritis (4.3\%). It is worth mentioning that there were no other common approach-related complications such as deep vein thrombosis, heterotopic ossification, iatrogenic nerve injury, or deep infection in our study population. ${ }^{28-30}$ This can be attributed primarily to the use of a single surgical approach with resultant reduction in soft tissue dissection, lesser time to recovery, and overall, less morbidity owing to the surgical approach. Meticulous attention to detail and the need for a high quality of reduction obtained on the table is beyond

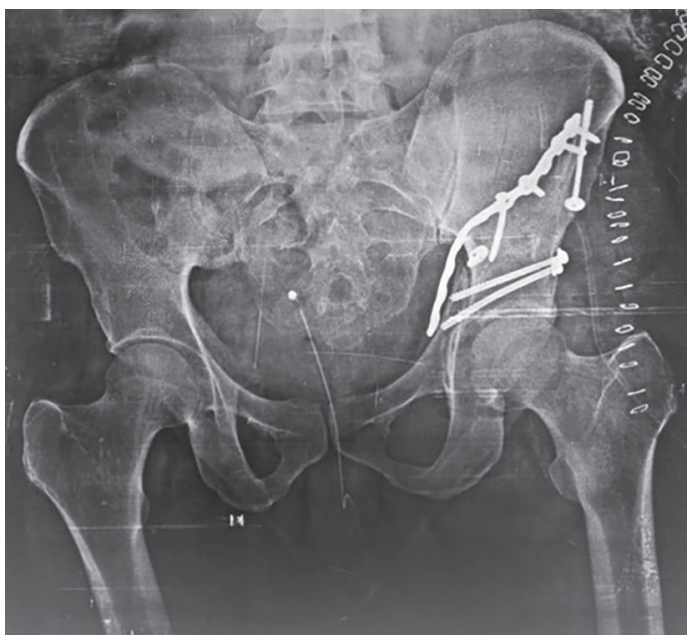

Fig. 10: Post-operative radiograph showing both fractures managed with iliofemoral approach

Table 2: Comparison of recent studies utilising single approach for managing bicolumn fractures of the acetabulum

\begin{tabular}{|c|c|c|c|}
\hline $\begin{array}{l}\text { Isaacson } \\
\text { et al. }{ }^{20}\end{array}$ & 2014 & $\begin{array}{l}\text { Modified stoppa } \\
\text { approach }\end{array}$ & $\begin{array}{l}36 \text { patients treated using } \\
\text { modified Stoppa. } 55 \% \\
\text { excellent MDA score }\end{array}$ \\
\hline $\begin{array}{l}\text { Xue } \\
\text { et al. }{ }^{14}\end{array}$ & 2016 & $\begin{array}{l}\text { Pubic symphysis } \\
\text { approach }\end{array}$ & $\begin{array}{l}7 \text { patients were treated } \\
\text { with PSA alone, but } 8 \\
\text { patients needed addition } \\
\text { of Kocher-Langenbeck } \\
\text { approach. } 43 \% \text { excellent } \\
\text { MDA score }\end{array}$ \\
\hline $\begin{array}{l}\text { Chen } \\
\text { et al. }^{15}\end{array}$ & 2018 & $\begin{array}{l}\text { Modified ilioinguinal } \\
\text { approach }\end{array}$ & $\begin{array}{l}22 \text { patients operated. } \\
63.63 \% \text { excellent MDA }\end{array}$ \\
\hline $\begin{array}{l}\text { Hue } \\
\text { et al. }^{21}\end{array}$ & 2018 & Iliofemoral approach & $\begin{array}{l}13 \text { patients operated. } \\
\text { Median HHS } 83.5 \text { (good). } \\
\text { Higher approach-related } \\
\text { complications than } \\
\text { comparable studies }\end{array}$ \\
\hline
\end{tabular}

doubt. These are the most important factors governing outcomes, whether radiological or clinical. ${ }^{31-33}$ The decision regarding the approach to be used must be driven primarily by fracture pattern and only secondarily by surgeon preference and training. Flexibility in choosing the approach, which requires a good understanding of the various approaches, thus forms an important cornerstone to providing good results.

\section{Limitations}

Randomisation was not done for this study, and all the patients were operated by a single surgeon. Bicolumnar fractures management by single approach has a long learning curve as proper patient selection is necessary as is the requisite experience and skill.

\section{Conclusion}

If a single approach is selected correctly based upon the morphology of fracture displacement, then good functional and surgical outcomes can be achieved. The HHS, MDA, and SF-36 scores, including MCS and PCS scores, showed comparable results between the different single approaches. Further studies 

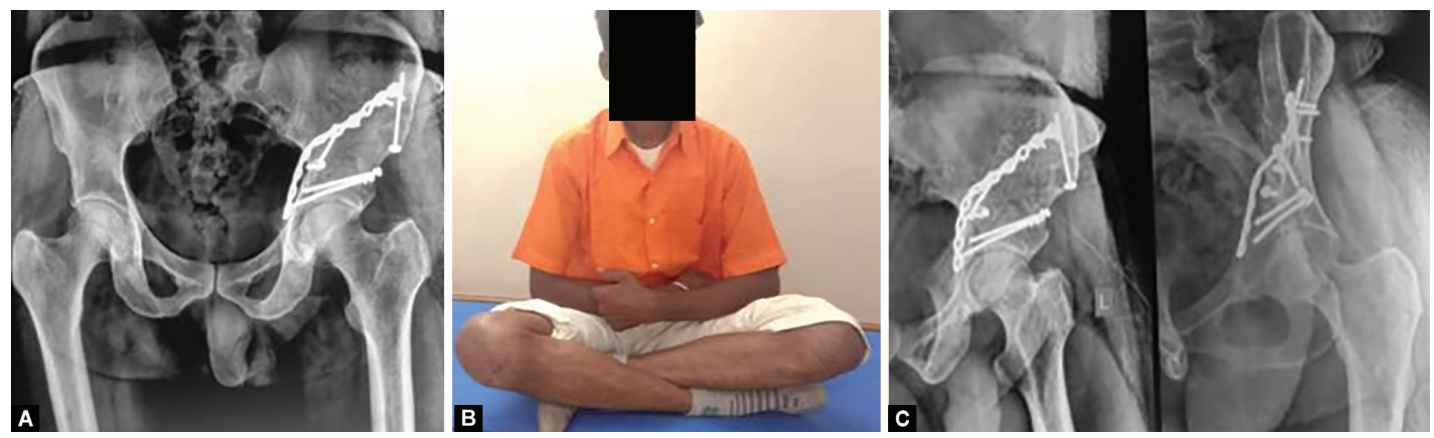

Figs $11 \mathrm{~A}$ to C: Good radiological and functional outcomes at 1 year with single iliofemoral approach

with a larger sample size will provide more data about single approach and reduce timing and soft tissue handling during surgery.

\section{Clinical Significance}

Traditionally multiple approaches are used for acetabulum fractures involving both columns but, with proper patient selection, the single approach can be used with good functional and surgical outcomes.

\section{References}

1. Peter RE. Open reduction and internal fixation of osteoporotic acetabular fractures through the ilio-inguinal approach: use of buttress plates to control medial displacement of the quadrilateral surface. Injury 2015;46(Suppl 1):S2-S7. DOI: 10.1016/S0020-1383(15)70003-3.

2. Khoury A, Weill $Y$, Mosheiff R. The Stoppa approach for acetabular fracture. Oper Orthop Traumatol 2012;24(4-5):439-448. DOI: 10.1007/ s00064-011-0093-z.

3. Letournel E. Diagnosis and treatment of nonunions and malunions of acetabular fractures. Orthop Clin North Am 1990;21(4):769-788. PMID: 2216407.

4. Hesp WL, Goris RJ. Conservative treatment of fractures of the acetabulum. Results after longtime follow-up. Acta Chir Belg 1988;88(1):27-32. PMID: 3376664.

5. Matta JM, Mehne DK, Roffi RA. Fractures of the acetabulum. Early results of a prospective study. Clin Orthop Relat Res 1986;(205):241250. PMID: 3698383.

6. Mcmurtry R, Walton D, Dickinson $D$, et al. Pelvic disruption in the polytraumatized patient: a management protocol. Clin Orthop Relat Res 1980;(151):22-30. PMID: 7418309.

7. Culemann U, Holstein JH, Köhler D, et al. Different stabilisation techniques for typical acetabular fractures in the elderly-a biomechanical assessment. Injury 2010;41(4):405-410. DOI: 10.1016/j. injury.2009.12.001.

8. Keel MJ, Ecker TM, Cullmann JL, et al. The Pararectus approach for anterior intrapelvic management of acetabular fractures: an anatomical study and clinical evaluation. J Bone Joint Surg $\mathrm{Br}$ 2012;94(3):405-411. DOI: 10.1302/0301-620X.94B3.27801.

9. Märdian S, Schaser KD, Hinz P, et al. Fixation of acetabular fractures via the ilioinguinal versus pararectus approach: a direct comparison. Bone Joint J 2015;97-B(9):1271-1278. DOI: 10.1302/0301620X.97B9.35403.

10. Hammad AS, El-Khadrawe TA. Accuracy of reduction and early clinical outcome in acetabular fractures treated by the standard ilio-inguinal versus the Stoppa/iliac approaches. Injury 2015;46(2):320-326. DOI: 10.1016/j.injury.2014.10.053.

11. Jakob M, Droeser R, Zobrist R, et al. A less invasive anterior intrapelvic approach for the treatment of acetabular fractures and pelvic ring injuries. J Trauma 2006;60(6):1364-1370. DOI: 10.1097/01. ta.0000208139.97474.f7.

12. Probe RO, Reeve RO, Lindsey RW. Femoral artery thrombosis after open reduction of an acetabular fracture. Clin Orthop Relat Res 1992(283):258-260. PMID: 1395255.

13. Hirvensalo E, Lindahl J, Kiljunen V. Modified and new approaches for pelvic and acetabular surgery. Injury 2007;38(4):431-441. DOI: 10.1016/j.injury.2007.01.020.

14. Guy P. Evolution of the anterior intrapelvic (Stoppa) approach for acetabular fracture surgery. J Orthop Trauma 2015;29(Suppl. 2):S1-S5. DOI: 10.1097/BOT.0000000000000269.

15. Ansari M. Is single Ilioinguinal approach the solution for treating all types of acetabular fractures-a prospective study of 54 patients. IOSR-JDMS 2013;8(5):26-34. DOI: 10.9790/0853-0852634.

16. Isaacson MJ, Taylor BC, French BG, et al. Treatment of acetabulum fractures through the modified Stoppa approach: strategies and outcomes. Clin Orthop Rel Res 2014;472(11):3345-3352. DOI: 10.1007/ s11999-014-3460-x.

17. Xue $Z$, Qin $H$, Ding $H$, et al. A novel approach for treatment of acetabular fractures. Med Sci Monit 2016;22:3680-3688. DOI: $10.12659 / \mathrm{msm} .898887$.

18. Chen K, Ji Y, Huang Z, et al. Single modified ilioinguinal approach for the treatment of acetabular fractures involving both columns. J Orthop Trauma 2018;32(11):e428-e434. DOI: 10.1097/ BOT.0000000000001303.

19. Matta JM. Operative treatment of acetabular fractures through the ilioinguinal approach: a 10-year perspective. J Orthop Trauma 2006;20(1):S20-S29. PMID: 16385203.

20. Prevezas N. Evolution of pelvic and acetabular surgery from ancient to modern times. Injury 2007;38(4):397-409. DOI: 10.1016/ j.injury.2007.01.035.

21. Hue AG, Gauthé R, Tobenas-Dujardin AC, et al. Complex fractures of the acetabulum: should the enlarged iliofemoral approach be abandoned? Results at 20 years' follow-up. Orthop Traumatol Surg Res 2018;104(4):465-468. DOI: 10.1016/j.otsr.2018.02.005.

22. Moroni A, Caja VL, Sabato C, et al. Surgical treatment of both-column fractures by staged combined ilioinguinal and Kocher-Langenbeck approaches. Injury 1995;26(4):219-224. DOI: 10.1016/00201383(95)00007-v.

23. Zhang $R$, Yin Y, Li S, et al. Minimally invasive treatment of both-column acetabular fractures through the Stoppa combined with iliac fossa approach. Scientific Rep 2017;7(1):1-9. DOI: 10.1038/s41598-01708724-1.

24. Suzuki T, Smith WR, Hak DJ, et al. Combined injuries of the pelvis and acetabulum: nature of a devastating dyad. J Orthop Trauma 2010;24(5):303-308. DOI: 10.1097/BOT.0b013e3181ca32af.

25. Osgood GM, Manson TT, O'Toole RV, et al. Combined pelvic ring disruption and acetabular fracture: associated injury patterns in 40 patients. J Orthop Trauma 2013;27(5):243-247. DOI: 10.1097/ BOT.0b013e31826c2751. 
26. Chin FY, Lo WH, Chen TH, et al. Fractures of posterior wall of acetabulum. Arch Orthop Trauma Surg 1996;115(5):273-275. DOI: 10.1007/BF00439052.

27. Mears DC, Velyvis JH, Chang CP. Displaced acetabular fractures managed operatively: indicators of outcome. Clin Orthop Relat Res 2003(407):173-186. DOI: 10.1097/00003086-20030200000026.

28. Iqbal F, Taufiq I, Najjad MK, et al. Functional and radiological outcome of surgical management of acetabular fractures in tertiary care hospital. Hip Pelvis 2016;28(4):217-224. DOI: 10.5371/hp.2016. 28.4.217.

29. Paksoy AE, Topal M, Aydin A, et al. Outcomes of surgical management of acetabular fractures treated with anterior approaches. Eurasian J Med 2019;51(3):257-261. DOI: 10.5152/eurasianjmed. 2019.0241.
30. Jindal K, Aggarwal S, Kumar $\mathrm{P}$, et al. Complications in patients of acetabular fractures and the factors affecting the quality of reduction in surgically treated cases. J Clin Orthop Trauma 2019;10(5):884-889. DOI: 10.1016/j.jcot.2019.02.012.

31. Çağlar Ö, Kamacı S, Bekmez Ş, et al. Mid-term results of displaced acetabulum fractures surgically treated using anterior intrapelvic approach (modified Stoppa). Ulus Travma Acil Cerrahi Derg 2020;26(1):130-136. DOI: 10.14744/tjtes.2019.03835.

32. Kizkapan TB, Misir A, Uzun E, et al. Comparison of acetabulum posterior wall fractures and fracture dislocations: dislocation does not affect clinical and radiological outcomes. Acta Orthop Belg 2018;84:117-122. PMID: 30462593.

33. Letournel E, Judet R. Fractures of the acetabulum. Springer Science \& Business Media; 2012 